\title{
Números fracionários - algumas ideias
}

\author{
Marilene Jacintho Müller ${ }^{1}$, Neda da Silva Gonçalves ${ }^{1}$, Márcia Moraes ${ }^{2}$ \\ ${ }^{1}$ Faculdade de Matemática, Pontifícia Universidade Católica do Rio Grande do Sul (Brasil) \\ Av. Ipiranga, 6681 - Porto Alegre, RS \\ ${ }^{2}$ Faculdade de Informática, Pontifícia Universidade Católica do Rio Grande do Sul (Brasil) \\ Av. Ipiranga, 6681 - Porto Alegre, RS
}

\begin{abstract}
Resumo. O objeto intitulado Números fracionários - algumas ideias, que está sendo enviado para participar do concurso de objetos de aprendizagem na Décima Conferência Latino-Americana de objetos de aprendizagem, induz o aluno universitário a refletir sobre a ideia de fração, um tópico de Matemática Básica, que frequentemente o impede de realizar atividades de seu curso as quais, em seus fundamentos, necessitam de um bom domínio deste conteúdo. A observação e pesquisas realizadas no Laboratório de Aprendizagem (LAPREN) da Pontifícia Universidade Católica do Rio Grande do Sul (PUCRS) com os alunos frequentadores, sobre os temas de Matemática Básica considerados por eles como dificeis, motivou a equipe do LAPREN a construir este objeto de aprendizagem. O presente trabalho pode, através de um enfoque diferenciado, trazer beneficios para leitores das mais variadas idades. Trabalhar a ideia de número fracionário e avaliar o valor de uma fração, são os objetivos que são visíveis na leitura do objeto que se propõe, de maneira simples, a dar a ideia de número fracionário através do conceito básico de unidade. O material apresenta figuras para auxiliar a compreensão do usuário, exercícios e indicações de leituras para aplicar e ampliar a ideia de fração apresentada no objeto.
\end{abstract}

\section{Considerações iniciais}

Consta na história, que inicialmente o homem não conhecia as frações, mas a necessidade de medir coisas do seu fazer diário, com precisão, levou-o a introduzir o uso das frações em suas atividades.

Atualmente é amplamente reconhecida a importância do trabalho com frações para a vida dos alunos, enquanto cidadãos. No entanto, via de regra, esse conteúdo não é facilmente compreendido e assimilado no Ensino Fundamental, o que traz sérias consequências na vida do estudante, em qualquer nível de escolaridade.

Cientes desta situação e vivenciando o dia- a- dia de universitários que apresentam lacunas na aprendizagem de frações, elaborou-se um objeto de aprendizagem intitulado Números fracionários - algumas ideias.

A intenção é apresentar o assunto de modo que possibilite e facilite a compreensão do usuário e que o permita interagir com o material de forma prazerosa.

O objeto foi elaborado para ser utilizado por alunos que, embora com o ensino básico concluído, apresentam algum problema ao trabalhar com números fracionários. 
As dificuldades não consistem especificamente apenas em operar frações, mas acima de tudo no tratamento de um número fracionário em seu valor concreto. Desta forma, a importância dada em trabalhar a ideia de número fracionário e avaliar o valor de uma fração, são perceptíveis na leitura do objeto que se propõe a dar a ideia de número fracionário através do conceito básico de unidade e apresentar exercícios e indicações de leitura para usar esse fato.

O conceito de unidade, em geral, é trabalhado nas séries iniciais do Ensino Fundamental. Naquele momento os alunos usam o símbolo "1" para expressar a unidade usada que se apresenta nas quantias representas por números que são resultados de contagem. A medida que os conteúdos vão sendo desenvolvidos nem sempre existe a exploração de uma unidade diferente daquela que fica parecendo ser a única ou pelo menos a única forma de representá-la. Nem que fiquem explícitas as variações que ocorrem em cada momento do estudo. Esse fato pode ser facilmente observado em situações, como por exemplo, quando um aluno vai representar graficamente uma função como a seno. Nesse momento ele tem dificuldade em determinar os valores que serão colocados no eixo das abscissas, quando bastava ter a ideia de usar $\pi / 2$ como unidade na marcação e o problema estaria resolvido.

A simplicidade foi a escolha para a apresentação do trabalho com o objetivo de levar o leitor, principalmente se é um estudante de Ensino Fundamental, a focar no conceito que está sendo trabalhado e não misturar ideias. É evidente que não há a pretensão de considerar que o problema estará resolvido com a realização do trabalho proposto, espera-se sim que consista do lançamento de um assunto para levar o aluno a refletir.

\section{Bases teóricas e metodológicas}

A experiência docente e o envolvimento com atividades ligadas ao ensino de Matemática, vivenciados ao longo dos anos. foram impulsionadores para o desenvolvimento do Objeto de Aprendizagem já nomeado.

Observa-se que os alunos chegam no Ensino Superior sem a compreensão dos diferentes significados associados aos números fracionários. A dificuldade com o conteúdo relativo às frações é, por vezes, o motivo do desanimo e desgosto pela Matemática manifestado pelos alunos. Uma das principais dificuldades encontradas. tanto por professores quanto por alunos, está na formulação do significado dos conteúdos matemáticos os quais geralmente são trabalhados mecanicamente e distante do contexto social do estudante. Os Parâmetros Curriculares Nacionais - PCN de Matemática (1998), destacam a necessidade de uma abordagem mais significativa dos conceitos, visando facilitar a compreensão por parte dos alunos.

"A seleção e organização de conteúdos deve levar em conta sua relevância social e sua contribuição para o desenvolvimento intelectual do aluno e não deve ter como critério apenas a lógica interna da Matemática.” (BRASIL,1998, p. 57).

Ainda nesta linha de pensamento, encontra-se na literatura:

"É necessário encontrar caminhos para levar o aluno a identificar quantidades fracionárias em seu contexto cotidiano e a apropriar-se da ideia do número fracionário correspondente, usando-os de modo significativo." (Bertoni, 2009, p.16).

No entanto, nota-se que a representação fracionária para expressar quantidades ou medidas são dificilmente empregadas no cotidiano. 
Neste contexto, propõe-se a utilização de um Objeto de Aprendizagem (AO), que possa oportunizar aos alunos apoio pedagógico na resolução de suas dúvidas sobre números fracionários e promover uma aprendizagem significativa. A certeza de que uma forma diferenciada de estudo pode contribuir para a formação completa de nossos estudantes tem levado a um intenso e gratificante trabalho de criação de objetos de aprendizagem virtuais. $\mathrm{O}$ objeto em questão foi elaborado para ser utilizado no ensino básico, tanto em sala de aula como em estudos extraclasse, e no ensino superior, em grupos de discussão sobre o tema, em sala de aula ou fora dela.

Na elaboração dos OAs, optou-se por utilizar a terminologia adotada pelo Learning Technology Standards Committee (LTSC) do Institute of Electrical and Electonics Engineers (IEEE). Além disso, fundamentaram seu desenvolvimento as orientações curriculares do Ministério da Educação e Cultura, que enfatizam a importância da tecnologia no processo educativo, e a teoria de Behar (2009), que defende as vantagens da utilização desta ferramenta.

O processo de criação dos OAs passa por diversas etapas: escolha do assunto, estudo, planejamento, contato com a área técnica (programação e diagramação), para verificação de possibilidades de apresentação, interação e organização. Elaborado, o material é entregue ao desenvolvedor para, então, ser armazenado no repositório e disponibilizado aos alunos. Mesmo aparentemente pronto, o objeto pode sofrer alterações pois, com o uso, o material é efetivamente avaliado e validado.

Pretende-se que os objetos construídos sejam interativos, conservando o que se considera muito importante: apresentação clara e simples dos conceitos matemáticos, por meio de situações concretas. Por essa razão, a construção desse tipo de material não é uma tarefa fácil.

\section{Descrição do objeto}

Ao iniciar a descrição do objeto Números fracionários - algumas ideias, cabe destacar as circunstâncias de sua criação. Por se tratar de um tema considerado "assunto de Ensino Fundamental", mas ser pensado inicialmente para resolver problemas apresentados por alunos que já superaram esse nível de estudos, foi desafiador considerar a possibilidade de sua construção. Não se tratava de simplesmente reproduzir cálculos já realizados, mas de chamar atenção para o fato de que, mudando unidades, o trabalho com números fracionários é apenas uma outra forma de visualizar uma quantidade.

Diluídas as dúvidas, a elaboração de um objeto de tamanho reduzido que aproximasse o aluno do assunto teoricamente já conhecido e que lhe permitisse o uso da intuição, mais do que da formalização, deu origem à forma do trabalho. Este é o primeiro de um grupo de objetos que pretende iniciar com simplicidade de linguagem o tratamento do assunto frações,

Como acontece com todos os objetos do repositório, suas páginas iniciais apresentam os objetivos, uma breve descrição e indicação de leitura complementar (Figura 1). A página que inicia o assunto propriamente dito está disposta a seguir (Figura 2) e traz uma separação do que poderia ser chamado de índice para o trabalho. 


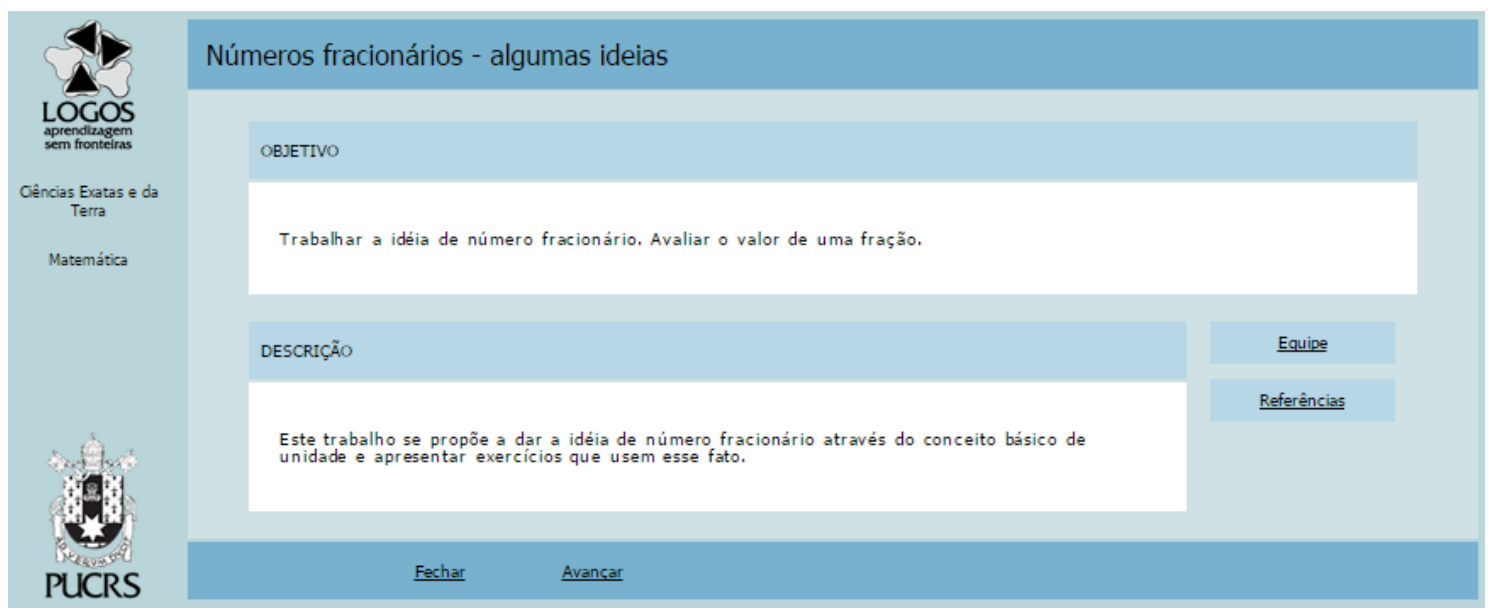

Figura 1.0 que é o Objeto

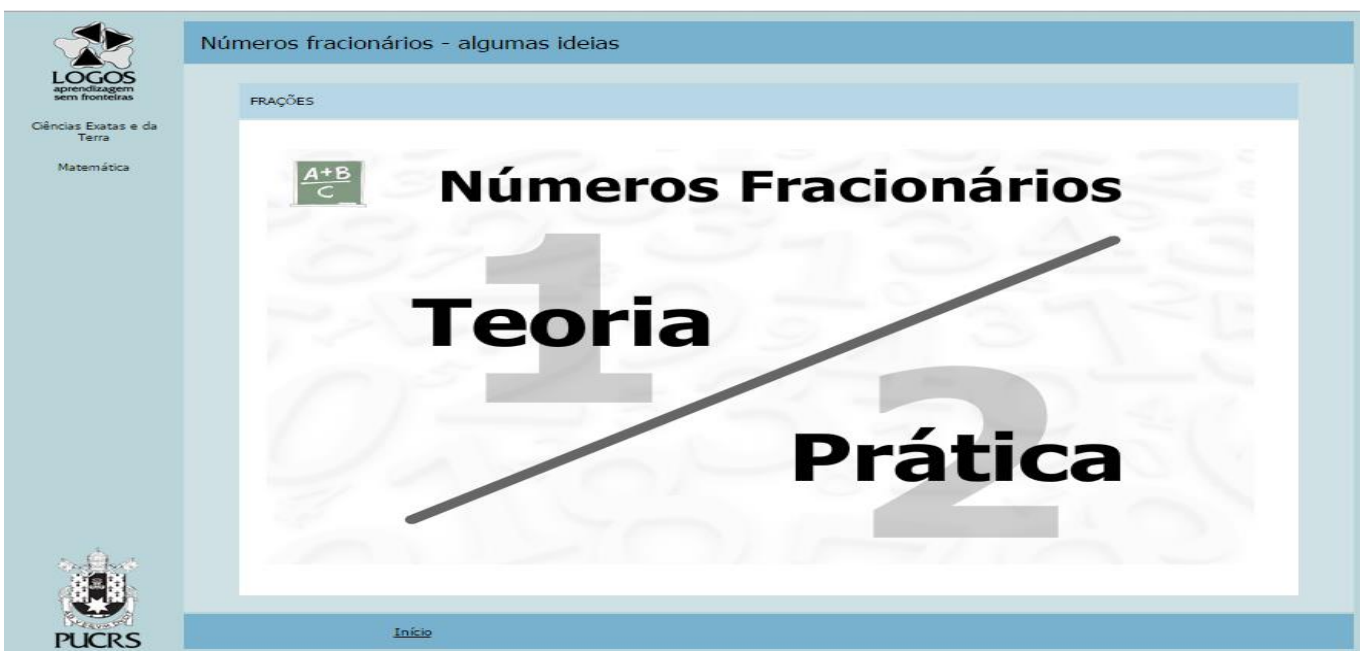

Figura 2. Índice

Segue-se então algumas quase atividades de tentativa com o objetivo de levar o estudante a reflexão sobre o fato da mudança de unidade (Figura 3). 
CBIE-LACLO 2015

Anais dos Workshops do IV Congresso Brasileiro de Informática na Educação (CBIE 2015)

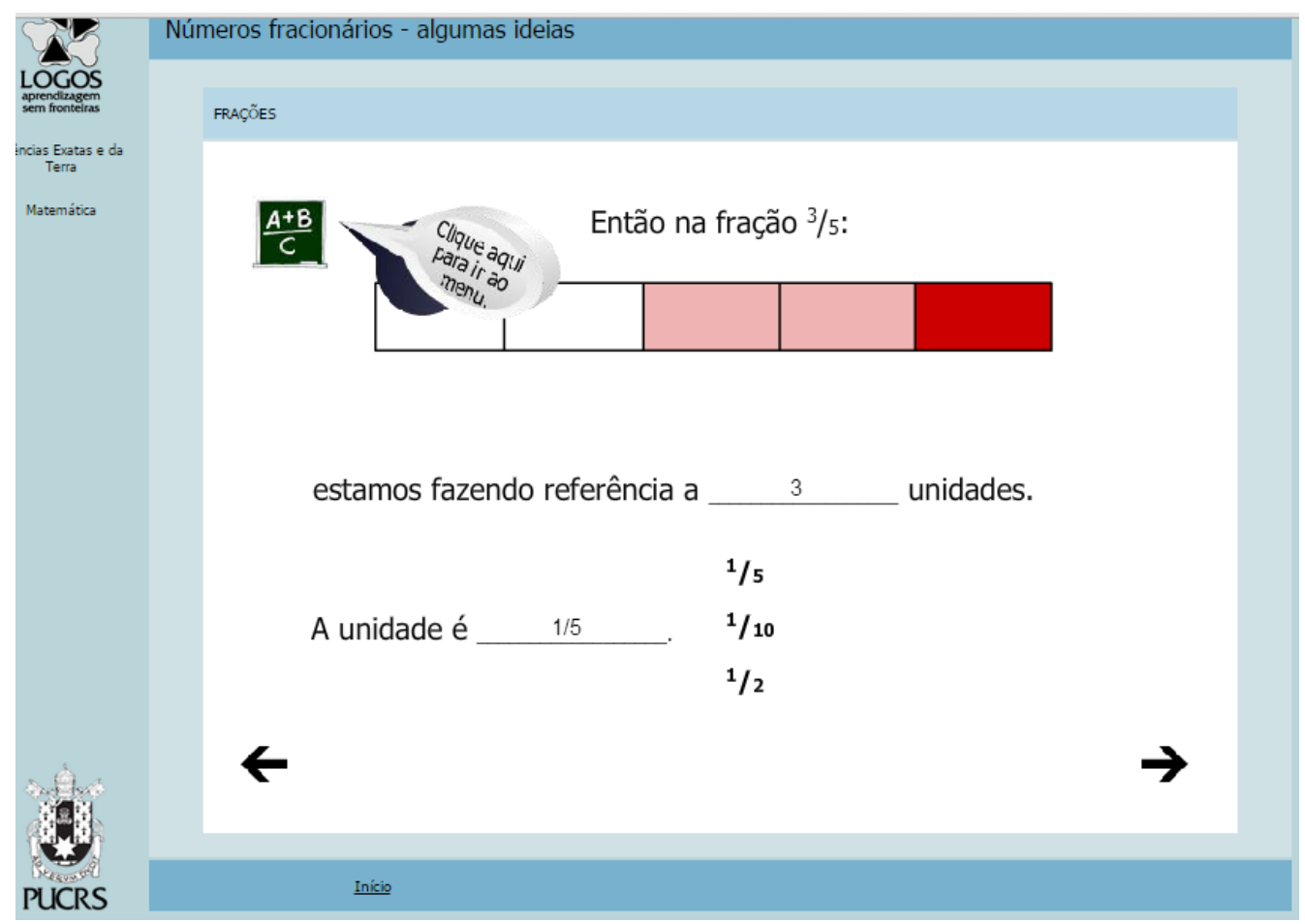

Figura 3. Atividade proposta

A equivalência entre os números fracionários também é chamada para o assunto (Figura 4) e como todas as abordagens é tratada rapidamente. Não há pretensão de considerar algum conteúdo como finalizado e sim que o trabalho iniciado seja um incentivo para continuar a estudar.

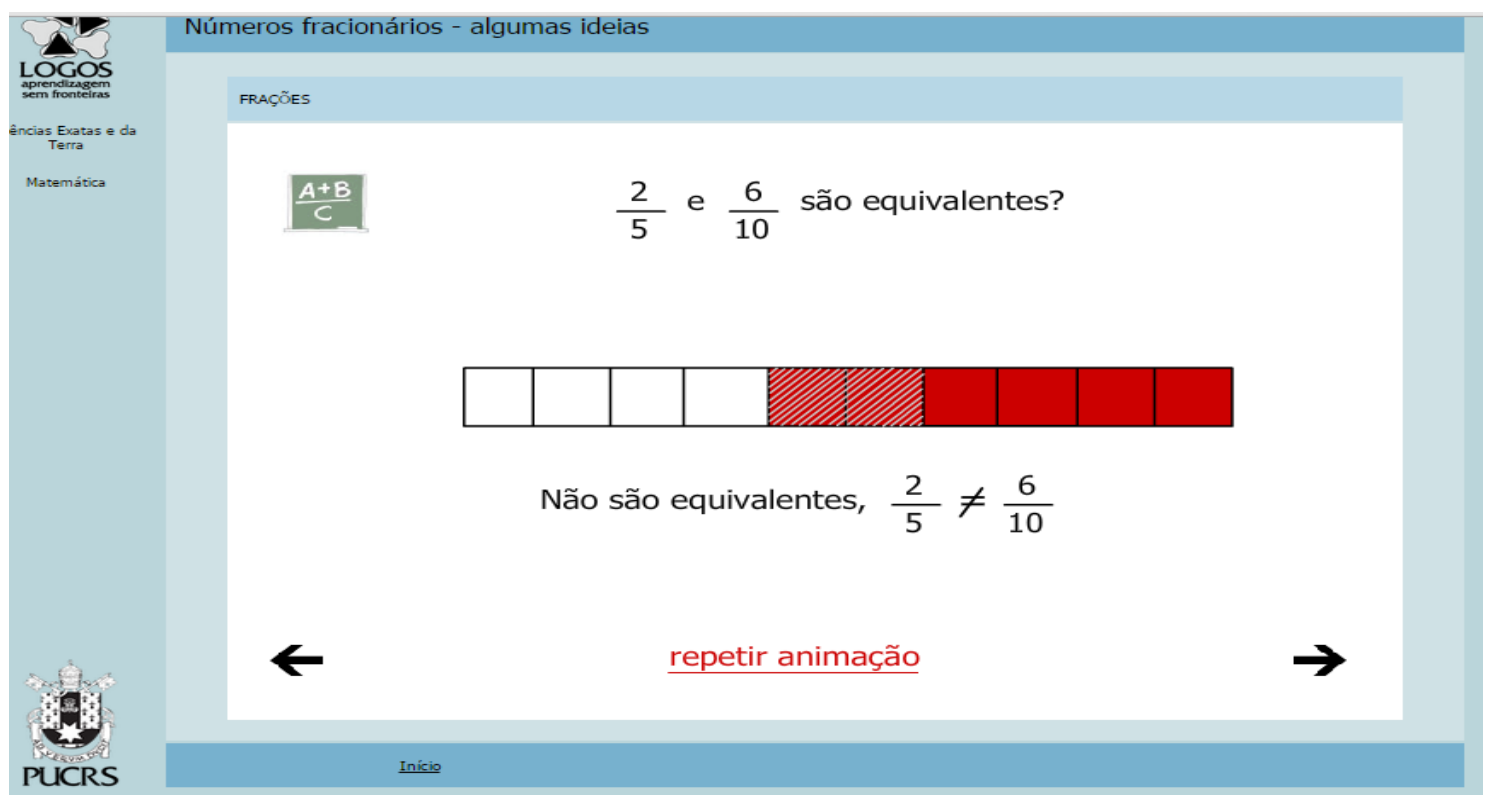

Figura 4. Atividade proposta 


\section{CBIE-LACLO 2015}

Anais dos Workshops do IV Congresso Brasileiro de Informática na Educação (CBIE 2015) incentivo.

Após o estudo do tema são sugeridos alguns exercícios para contribuir no pretendido

Ao finalizar é sugerida uma bibliografia e vídeos para que os alunos estabeleçam relações entre o que trabalharam e o que assistem ou ouvem em outros meios que não os escolares.

\section{Considerações finais}

Nos dias atuais, com a visível evolução tecnológica e a influência inevitável dessa evolução no campo educacional, muito tem se falado sobre utilização de Objetos de Aprendizagem (OAs), tanto na educação a distância como no apoio ao ensino presencial. Tais recursos digitais vêm sendo aplicados em diferentes áreas do conhecimento, permitindo que novas práticas ampliem antigas possibilidades. Especificamente na área da educação, eles possibilitam que conteúdos sejam abordados de diversas formas, de modo que auxiliem no desenvolvimento da autonomia do estudante. Segundo Cazalis (2007), em um momento em que se preconizam mudanças, a mais urgente e fundamental é o desenvolvimento de estratégias de autoaprendizagem. Entende-se que propor Objetos de Aprendizagem como recurso de estudo é uma forma concretas de resposta a tal compromisso.

Depoimentos de usuários do objeto destacam que com clareza e simplicidade o material é grande facilitador para a compreensão do conceito de fração, o que leva a crer que os objetivos propostos na construção deste recurso pedagógico foram alcançados.

É muito gratificante, ao avaliar esse objeto, verificar que tem sido utilizado por alunos em cursos de graduação, que sentem necessidade de revisar alguns conceitos, por alunos de ensino básico e ainda por estagiários do curso de Licenciatura em Matemática em suas aulas do estágio. Em todas as ocasiões tem servido como incentivo para a continuidade do estudo com números fracionários.

\section{Referências}

BERTONI, N.E. Educação e Linguagem Matemática IV: Frações e Números Fracionários. Brasília: Universidade de Brasília, 2009.

BRASIL.MEC. Secretaria de Educação Fundamental. Parâmetros Curriculares Nacionais: terceiro e quarto ciclos do ensino fundamental - Brasília: MEC, 1998.

BRASIL. (2006) PCNs + (Ensino Médio.) Orientações Educacionais Complementares aos Parâmetros Curriculares Nacionais. Ciências da natureza, matemática e suas tecnologias. Brasília: Ministério da Educação, Secretaria de Educação Básica.

BEHAR, P.A. (org.). (2009) Modelos Pedagógicos em Educação a Distância. Porto Alegre: Artmed. 
CAZALIS, P. (2007) Menos aula, mais conhecimento. PUCRS Informações, Porto Alegre, n.135, p.24-25, jul./ago.

IEEE.(2008). "IEEE Learning Object Metadata". Disponível em: http://ltsc.ieee.org/wg12/, Agosto.

IEEE Learning Technology Standards Committee (LTSC). Draft Standard for Learning Object Metadata, Institute of Electrical and Electronics Engineers, Inc, 2000. 